\title{
ACERCA DO INTERESSE DE HANS-GEORG GADAMER PELO DIREITO
}

\author{
ON HANS-GEORG GADAMER'S INTEREST IN LAW
}

\section{SOBRE EL INTERÉS DE HANS-GEORG GADAMER POR EL DERECHO}

\author{
MARIANA PIMENTEL FISCHER PACHECO \\ https://orcid.org/0000-0003-3217-5756 / http://lattes.cnpq.br/8564532125332975 / marianafisch@gmail.com \\ Universidade de São Paulo, USP. \\ São Paulo, SP, Brasil.
}

ALESSANDRA MACEDO ASFORA

https://orcid.org/0000-0002-4916-1425 / http://lattes.cnpq.br/1084759390201724 / alemacedolins@yahoo.com.br Universidade Federal da Paraíba, UFPB. João Pessoa, PB, Brasil.

\begin{abstract}
RESUMO
No segundo pós-guerra, na Alemanha, juristas como Josef Esser, Friedrich Müller e Arthur Kaufmann se interessaram pela hermenêutica filosófica gadameriana e, inspirados nela, buscaram repensar a interpretação da norma jurídica. 0 contexto de recepção os levou, contudo, a descuidarem de certos aspectos do trabalho do filósofo: curiosamente, esses juristas forneceram pouca atenção às reflexões específicas de Gadamer sobre o direito. É justamente essa dimensão obscurecida do pensamento gadameriano que buscaremos, aqui, trazer à tona. Lembraremos que, partir de um questionamento acerca de ontologia e ética, Gadamer observa a atividade do jurista e a conecta à phrónesis aristotélica. Concluiremos que os juristas, hoje, têm muito a aprender com suas lições acerca do componente ético presente na necessária tarefa de adaptação da norma ao caso concreto.
\end{abstract}

Palavras-chave: Direito; Ética; Hermenêutica; Prudência.

\begin{abstract}
In the second postwar period, in Germany, legal thinkers such as Josef Esser, Friedrich Müller and Arthur Kaufmann became interested Gadamer's philosophical hermeneutics. Inspired by it, they tried to rethink the interpretation of the norm. The context of reception led these jurists, however, to neglect some aspects of the philosopher's work. Surprisingly, they paid little attention to what Gadamer has specifically written on legal hermeneutics. We intend to reinvigorate this neglected dimension of his work. Gadamer thoughts on Law are rooted in an ontological and ethical perspective; from this point of view he insists on the importance of connecting the activities of jurists and the Aristotelian phronesis. We will conclude that jurists today have a lot to learn with his lessons on the ethical component of the activity of adapting the norm to the case.
\end{abstract}

Keywords: Law; Ethics; Hermeneutics; Prudence.

\section{RESUMEN}

En la segunda posguerra, en Alemania, juristas como Josef Esser, Friedrich Müller y Arthur Kaufmann se interesaron por la hermenéutica filosófica gadameriana y, inspirados en ella, buscaron repensar la interpretación de la norma jurídica. El contexto de recepción los llevó, sin embargo, a descuidar ciertos aspectos del trabajo del filósofo: curiosamente, esos juristas proporcionaron poca atención a las reflexiones específicas de Gadamer sobre el derecho. Es justamente esa dimensión oscurecida de lo que pensamos gadameriano que buscaremos aquí traer a la superficie. Recordemos que, partir de un cuestionamiento acerca de ontología y ética, Gadamer observa la actividad del jurista y la conecta a la phrónesis aristotélica. Concluimos que los juristas, hoy, tienen mucho que aprender con sus lecciones acerca del componente ético presente en la necesaria tarea de adaptación de la norma al caso concreto.

Palabras-clave: Derecho; Etica; Hermenéutica; Prudencia.

\footnotetext{
${ }^{1}$ Agradecemos pelos constantes comentários Gustavo Just, que impulsionaram e refinaram o trabalho de pesquisa que deu origem a esse artigo.
} 


\title{
SUMÁRIO
}

INTRODUÇÃO; 1 REFLEXÕES GADAMERIANAS ACERCA DA ATIVIDADE DO JUIZ EM VERDADE E MÉTODO; 2 A IMPORTÂNCIA PHRÓNESIS ARISTOTÉLICA; 3 O SABER DA PRAXIS; CONCLUSÃO; REFERÊNCIAS.

\section{INTRODUÇÃO}

Para o filósofo e filólogo Hans-Georg Gadamer, a interpretação é um existencial. Estar no mundo é atribuir sentido. Quem interpreta carrega expectativas de sentido construídas historicamente e por meio de linguagem. Tais antecipações ou pré-compreensões se relacionam de maneira circular e dinâmica com a compreensão atual, um elemento pressupõe o outro e ambos impulsionam o movimento.

Não há como fugir de uma visão do todo, assim como de noções pré-concebidas que temos sobre o mundo; a compreensão pode, contudo, abrir-se à alteridade da coisa em questão. Para tanto, é necessário posicionar-se no círculo hermenêutico de maneira adequada, com consciência das próprias antecipações de sentido e da força que a história exerce. Consciência histórica significa atenção à maneira pela qual o passado determina nossa compreensão presente. Apenas se tivermos esse tipo de sensibilidade poderemos aprender a deixar a coisa falar por ela mesma, isto é, somente assim poderemos nos abrir ao seu potencial de fundar novos mundos de sentido.

\begin{abstract}
Esse deixar-se determinar assim pela própria coisa, evidentemente, não é para um intérprete uma decisão heroica tomada de uma vez por todas, mas verdadeiramente a tarefa primeira, constante e última. Pois o que importa é manter a vista atenta à coisa através de todos os desvios a que se vê constantemente submetido o intérprete em virtude das ideias que lhe ocorrem ${ }^{2}$
\end{abstract}

$\mathrm{Na}$ história do pensamento jurídico moderno, contudo, o problema da interpretação foi colocado de maneira bastante distinta. Desde o início do século XIX, os juristas tentam a todo custo fornecer ao direito o status de cientificidade e, para tanto, buscaram estabelecer cânones seguros para a interpretação da norma. Savigny foi quem primeiro sistematizou os quatro métodos de interpretação ${ }^{3}$ (gramatical, sistemático, histórico e teleológico), os quais

\footnotetext{
${ }^{2}$ GADAMER, Hans Georg. Verdade e método I; traços fundamentais de uma hermenêutica filosófica. Petrópolis: Ed. Vozes, 2002. p. 356.

${ }^{3}$ Não por acaso juristas das mais diversas linhagens, como Karl Larenz (1997), Raffaele de Giorgi (2017), Friedrich Müller (2005) e Robert Alexy (2001) tomam Savigny como ponto de partida em suas reflexões sobre a interpretação no direito moderno.
} 
determinariam a descoberta (e não criação) dos verdadeiros institutos jurídicos, isto é, daqueles que traduziriam o "espírito do povo"4.

No período subsequente, o formalismo jurídico ${ }^{5}$ se tornou a corrente de mais destaque na tradição romano-germânica. Os formalistas mais entusiasmados insistiam que o direito seria uma ciência já que se pautaria em um raciocínio semelhante ao matemático: os intérpretes seriam capazes de descobrir o sentido unívoco da norma a qual, em um segundo momento, seria aplicada ao caso concreto por meio de uma subsunção simples. Tal metodologia estabeleceria limites inequívocos ao arbítrio dos juízes.

Podemos, desde já, entrever uma tensão entre a hermenêutica filosófica gadameriana e as teorias da interpretação na história das ideias jurídicas: de um lado um esforço de abertura à coisa ela mesma, de outro, a busca por controle metódico de decisões.

No segundo pós-guerra, uma forte crítica à racionalidade moderna toma conta de diversos campos do saber e invade também o debate entre juristas. Os teóricos do direito falam em crise do positivismo e em uma guinada interpretativa ${ }^{6}$. As diversas perspectivas que surgem nesse momento problematizam a ideia de que um raciocínio formal, puramente dedutivo e axiologicamente neutro conectaria a regra geral a decisões concretas.

Decerto, a crítica ao raciocínio formal não é nova (está presente nos escritos tardios de Jhering, na perspectiva sociológica de Ehrlich e Kantorowicz e, também, no positivismo atípico de Kelsen ${ }^{7}$ ), a novidade aqui é que tal crítica passa a ocupar o centro das discussões entre juristas e é associada a ideias sobre linguagem advindas da tradição hermenêutica e também wittgensteiniana. Surgem, então, tendências que vão desde o realismo norte-americano e escandinavo (os mais céticos dentre eles afirmam que não há qualquer relação entre norma abstrata e decisão judicial) até tentativas de reconstruir o modelo formal de raciocínio do direito, principalmente, na tradição analítica anglo-saxônica (que frequentemente faz uso de ideias de Wittgenstein).

\footnotetext{
${ }^{4}$ SAVIGNY, Friedrich Carl von. Sistema del Derecho Romano Actual. Alicante: Biblioteca Virtual Miguel de Cervantes, 2009.

${ }^{5} \mathrm{~A}$ tradição formalista tem como precursores exegetas franceses, envolve ideias do segundo Savigny e da Jurisprudência dos Conceitos de Puchta e atinge sua versão mais sofisticada com o positivismo de Kelsen (Kelsen não é, contudo, um formalista e um positivista típico, especialmente por conta de sua peculiar teoria da interpretação).

${ }^{6}$ Para um aprofundamento ver CALSAMIGLIA, Albert. Postpositivismo. In: Doxa, n. 17/18. Alicante: Universidad de Alicante, 2005.

${ }^{7}$ Acompanhamos, aqui, Samuel Barbosa, que mostra que Kelsen, em sua teoria da interpretação, desafiou "representações jusnaturalistas e positivistas, para indicar a abertura para o esforço construtivo renovado da dogmática" ( $\mathrm{p}$ 83). BARBOSA, Samuel. Jus Cogens como aporia: o crepúsculo do direito internacional clássico. Revista Brasileira de Filosofia, v. 58, n 233, p 37-85, 2009.
} 
Interessa-nos atentar para um movimento que, nesse momento, ganha vigor na Alemanha, o qual Gustavo Just ${ }^{8}$ chama de Jurisprudência Hermenêutica9. Juristas como Josef Esser, Friedrich Müller, Arthur Kaufmann e Karl Larenz e Peter Häberle se interessaram por Gadamer e, inspirados em suas ideias, tentaram repensar a interpretação no direito. Ocorre que, apesar de críticos ao formalismo jurídico, esses juristas permaneceram, em diversos aspectos, presos a concepção de método formulada por seus adversários.

Assim, ideias bastante difundidas pela filosofia gadameriana (como pré-compreensão, fusão de horizontes, círculo hermenêutico, unidade entre compreensão, interpretação e aplicação) deram suporte a perspectivas acerca do direito que questionam raciocínio silogístico, bem como a possibilidade de determinação unívoca do sentido das normas jurídicas, mas que mantiveram a ambição de estabelecer um controle metódico de decisões. Dificuldades de se desvencilhar por completo de tal projeto levaram os juristas da Jurisprudência Hermenêutica a construírem modelos de interpretação bastante diferentes daquele defendido por Gadamer, os quais reproduzem a imagem de linearidade, hierarquização e compartimentação de tarefas em processos decisórios $^{10}$.

Em Esser, por exemplo, podemos observar dois movimentos contraditórios: inicialmente ele se apropria da tese gadameriana da unidade entre compreensão, interpretação e aplicação e, em um segundo momento, recusa essa mesma tese ao definir o processo decisório como um processo de conhecimento e não de aplicação. Ele escreve, assim, sobre a tarefa do intérprete: “a sua atitude não corresponde a um processo de aplicação, no sentido de uma preparação farmacêutica, por melhor que seja o seu fundamento, e sim a um processo de conhecimento"11.

No Brasil, salvo raras exceções (como a leitura de Gadamer realizada por Nelson Saldanha e por Gustavo Just), a recepção de Gadamer por juristas ocorreu de maneira um pouco desajeitada. Nelson Saldanha escreve:

0 recente surgimento, na cultura filosófica europeia, da corrente hermenêutica, com base no pensamento de Gadamer e de outros, tem feito despontar alguns reflexos no Brasil. Mas ainda muito pequenos, dando-se inclusive casos em que certos professores "falam" dessa corrente sem desamarrar das vistas dogmáticas tradicionais, ou mesmo (o que é absurdo) tentando "adotar" seus supostos gerais sem se desligar do juspositivismo nem do normativismo. ${ }^{12}$

\footnotetext{
8 JUST, Gustavo. Interpretando as teorias da interpretação. São Paulo: Saraiva, 2014.

9 JUST, Gustavo. Interpretando as teorias da interpretação. São Paulo: Saraiva, 2014

10 JUST, Gustavo. Interpretando as teorias da interpretação. São Paulo: Saraiva, 2014.

${ }^{11}$ ESSER, Josef. Precomprensione e scelta del método nel processo di individuazione del diritto.

Camerino: Edizioni Scientifiche Italiane, 1983. p. 73-74.

12 SALDANHA, Nelson: Ordem e Hermenêutica. Rio de Janeiro: Renovar, 2003. p. 295.
} 
Concentremo-nos, entretanto, na recepção de Gadamer na Alemanha. Como dito, o contexto, que demandava a criação de estratégias para controle método de decisão, levou os juristas da Jurisprudência Hermenêutica a incorrer em contradições ou a descuidar de dimensões fundamentais da filosofia gadameriana. Parece-nos emblemático o fato de que esses juristas forneceram pouca atenção justamente às reflexões específicas de Gadamer sobre o direito.

Buscaremos, aqui, revigorar esse aspecto do trabalho do filósofo, obscurecido pela tradição juridicista e, nesse sentido, indagaremos: o que mesmo Gadamer escreveu sobre o direito? 0 que os juristas podem apreender, hoje, com as lições gadamerianas sobre o caráter exemplar da hermenêutica jurídica e sua relação com a phrónesis aristotélica? Argumentaremos que talvez as lições gadamerianas nos ensinem a olhar para o direito não com a ambição de controle, mas com o objetivo de abertura a seu componente ético.

Esse artigo se estrutura da seguinte maneira. Inicialmente, situaremos cronologicamente e no âmbito de Verdade e Método as reflexões gadamerianas sobre o direito. Em seguida, tentaremos compreender por que o filósofo insiste que a hermenêutica jurídica tem um caráter exemplar e, do mesmo modo, examinaremos a importância de sua tese acerca da unidade entre compreensão, interpretação e aplicação. Investigaremos, então, a conexão estabelecida por Gadamer entre hermenêutica jurídica, ética e phrónesis aristotélica. Concluiremos que retomar as lições gadamerianas significa legitimar um saber sobre o direito mais cuidadoso com a prática e com sua conexão com a ética.

\section{REFLEXÕES GADAMERIANAS ACERCA DA ATIVIDADE DO JUIZ EM VERDADE E MÉTODO}

Gadamer não era um estudioso do direito, sua formação foi em filosofia e filologia grega, seus principais professores (Natorp, Hartmann, Heidegger) também não eram juristas. Até 1960, Gadamer não havia elaborado um trabalho inteiramente dedicado ao tema, apenas mencionava-o brevemente. Nesse ano, todavia, publica seu principal livro, Verdade e Método, no qual escreve um capítulo de fundamental importância sobre hermenêutica jurídica ${ }^{13}$.

\footnotetext{
${ }^{13}$ Cf. GRONDIN, Jean. Gadamer's Interest for legal hermeneutics. In: Law's hermeneutics: other investigations, Routledge : Oxford, 2017, 48-62. GRONDIN, Jean. Gadamer: una biografia. Milão: Bompiani, 2004. GADAMER, Hans Georg. Verdade e método I: traços fundamentais de uma hermenêutica filosófica. Petrópolis: Ed. Vozes, 2002.
} 
A primeira parte de Verdade e Método gravita em torno da experiência da arte, nos capítulos sobre o juízo e o gosto existem rápidas referências ao direito. A segunda parte do livro cuida da compreensão nas ciências humanas, há menções ao direito na seção acerca da legitimidade dos preconceitos, mas a investigação se aprofunda somente no capítulo intitulado "O Significado Paradigmático da Hermenêutica Jurídica".

Gadamer não aborda, aqui, casos ou conceitos jurídicos, ele examina o caráter exemplar da práxis no direito com o objetivo de elucidar algo que seria universal, isto é, alguma coisa que estaria sempre presente no acontecimento da compreensão. O que isso quer dizer?

Em primeiro lugar, devemos notar que definir de modo preciso o significado do termo “exemplar” em Verdade e Método não é uma tarefa fácil, já que Gadamer o utiliza em acepções distintas. Em alguns trechos toma o vocábulo por empréstimo da estética de Kant e lembra que o juízo do gosto tem "necessidade exemplar"14. Não é, entretanto, com esse sentido que o emprega para se referir à hermenêutica jurídica.

Ainda na parte sobre estética, o termo "exemplo" ganha outro significado. Gadamer escreve sobre o "exemplo do trágico" e conclui que nele estaria o ser mesmo do estético. Tal como o trágico, a hermenêutica jurídica seria também exemplar, pois constituiria um paradigma capaz de elucidar algo que estaria lá sempre que nos engajamos na tarefa de compreensão do mundo. Sobre o caráter exemplar do trágico para compreensão da obra de arte, Gadamer afirma:

O trágico é um fenômeno fundamental, uma figura de sentido que não ocorre somente na tragédia, na obra de arte trágica no sentido estrito da palavra, mas pode ter seu lugar também noutros gêneros de arte, principalmente nas obras épicas. Na verdade, nem se trata de um fenômeno especificamente artístico, uma vez que se encontra também na vida [...] 0 ser estético havia se tornado visível para nós como jogo e representação. Assim podemos interrogar também a teoria do jogo trágico, que é a poética da tragédia, sobre a essência do trágico [...] 0 que vale assim para o trágico pode ser aplicado também para um âmbito bem mais amplo ${ }^{15}$.

No que concerne à hermenêutica jurídica como exemplo no processo de compreensão, o filósofo esclarece:

O modelo da hermenêutica jurídica mostrou-se, pois efetivamente fecundo. Quando se sabe autorizado a realizar a complementação do direito, dentro da

\footnotetext{
${ }^{14}$ GADAMER, Hans Georg. Verdade e método I: traços fundamentais de uma hermenêutica filosófica. Petrópolis: Ed. Vozes, 2002, p 186.

${ }^{15}$ GADAMER, Hans Georg. Verdade e método I: traços fundamentais de uma hermenêutica filosófica. Petrópolis: Ed. Vozes, 2002, p. 186-187.
} 
função judicial e frente ao sentido original de um texto legal, o que faz o jurista é exatamente aquilo que ocorre em qualquer tipo de compreensão ${ }^{16}$.

A hermenêutica jurídica interessa Gadamer na medida em que o juiz realiza uma complementação do texto normativo sempre que o conecta a um caso concreto, tal atividade de complementação ou, como veremos, de mediação ilustra algo que ocorre em toda compreensão. Assim, tal como o trágico, a hermenêutica jurídica mostraria o universal.

Ora, ao afirmar que a hermenêutica jurídica é exemplar ou paradigmática, Gadamer quer dizer que filósofos e epistemólogos podem aprender com aquilo que os juristas práticos (especialmente o juiz) fazem, por vezes, sem plena consciência do que exatamente fazem (isto é, juristas práticos sabem fazer, aprenderam com a experiência e não por meio de lições abstratas). Como vimos, essa questão foi negligenciada pelos juristas-teóricos da Jurisprudência Hermenêutica. Devemos insistir, aqui, que tal desatenção não foi de modo algum fruto do acaso. Lembremos que o capítulo de Verdade e Método sobre o direito está situado em uma seção intitulada "A reconquista do problema fundamental da hermenêutica". A palavra "reconquista" sugere, aqui, que estamos diante de uma questão que foi deixada de lado também na história da filosofia.

De fato, segundo Gadamer ${ }^{17}$, Schleiermacher e Dilthey teriam levado a hermenêutica a exercer uma função metodológica, isto é, teriam atribuído a ela a tarefa de criar um método capaz de impor limites ao relativismo ou o subjetivismo nas ciências humanas. Essas últimas, aos ouvidos dos epistemólogos dos séculos XIX e XX, seriam pouco confiáveis já que seus resultados estavam distantes do modelo de objetividade das ciências naturais.

O filósofo questiona tanto o propósito da hermenêutica de estabelecer uma metodologia capaz de exercer esse tipo de controle, como também a constatação de que a contaminação do intérprete pelo contexto e pela tradição seria necessariamente uma má notícia. A hermenêutica gadameriana mostra que as ciências humanas jamais conseguirão escapar do seu radical pertencimento à história. 0 equívoco estaria justamente em propor que os resultados das pesquisas nessa área devem ser independentes da historicidade dos interpretes.

Em vez da busca obsessiva pela elaboração de métodos supostamente capazes de assegurar a objetividade em termos semelhantes aos das ciências naturais, seria mais produtivo perguntar em que medida o enraizamento histórico é indispensável para as humanidades. Eis o

\footnotetext{
${ }^{16}$ GADAMER, Hans Georg. Verdade e método I: traços fundamentais de uma hermenêutica filosófica. Petrópolis: Ed. Vozes, 2002, 446.

${ }^{17}$ GADAMER, Hans Georg. Verdade e método I: traços fundamentais de uma hermenêutica filosófica. Petrópolis: Ed. Vozes, 2002.
} 
problema hermenêutico fundamental, negligenciado tanto pela hermenêutica de Schleiermacher e Dilthey nos séculos XIX e XX como pela tradição juridicista.

No contexto de tal questionamento, especificamente no capítulo de Verdade e Método sobre a hermenêutica jurídica, Gadamer examina a distinção formulada pelo jurista italiano Emilio Betti entre três tipos de interpretação: cognitiva, normativa e reprodutiva. A tarefa cognitiva da filologia e da história teria como objetivo a determinação epistemológica do significado. A normativa, que é atribuída ao direito e à teologia, estaria ligada à função decisória e, nesse sentido, levaria em conta um fator adicional, a aplicação. A terceira tarefa da interpretação é a reprodutiva e se refere à atividade do tradutor e de todos aqueles envolvidos com as artes cênicas, especialmente na interpretação teatral e musical ${ }^{18}$.

Betti insiste que a tarefa do juiz e do historiador do direito seriam fundamentalmente diversas: o propósito do historiador seria cognitivo ou teórico, por outro lado, o juiz teria ainda uma outra tarefa, a de aplicação da norma jurídica ao caso concreto ${ }^{19}$. Muito embora consciente das diversas atribuições do juiz e do historiador, Gadamer defende a unidade das atividades cognitivas e aplicativas: apesar das consequências práticas da interpretação do historiador não serem as mesmas que as implicações de uma decisão judicial, aquele jamais será capaz de conhecer uma lei do passado sem que ao mesmo tempo a aplique a uma situação concreta do presente ${ }^{20}$.

A repartição de atividades proposta por Betti (cognição, aplicação e reprodução) não ocorre por acaso. Recordemos que a sua teoria de hermenêutica foi publicada em 1955 e que, nesse momento, o jurista italiano buscava se opor a noção de pré-compreensão defendida por pensadores como Heidegger e Bultmann. Betti foi um dos primeiros críticos ao antimetodologismo da hermenêutica filosófica ${ }^{21}$.

Lembremos ainda que tal tentativa de compartimentalização de tarefas está profundamente conectada ao propósito dos juristas de controlar decisões e, como dito, foi uma constante na história das ideias jurídicas, desde Montesquieu (segundo o qual ao legislador caberia criar a lei e ao juiz, que seria a "boca da lei", somente aplica-la) até Esser, passando

${ }^{18}$ Cf. GADAMER, Hans Georg. Verdade e método I: traços fundamentais de uma hermenêutica filosófica. Petrópolis: Ed. Vozes, 2002. BETTI, Emilio. Teoria generale dell' interpretazione. 2 vols. Milão: Giuffrè, 1955.

${ }^{19} \mathrm{BETTI}$, Emilio. Teoria generale dell'interpretazione. 2 vols. Milão: Giuffrè, 1955.

${ }^{20}$ GADAMER, Hans Georg. Verdade e método I: traços fundamentais de uma hermenêutica filosófica. Petrópolis: Ed. Vozes, 2002

${ }^{21}$ Cf. BETTI, Emilio. Teoria generale dell' interpretazione. 2 vols. Milão: Giuffrè, 1955. GRONDIN, Jean. La hermenéutica como ciencia rigurosa según Emilio Betti (1890-1968). Revista Co-herencia Vol. 8, No 15 Julio - Diciembre 2011, pp. 15-44. Medellín, Colombia 
por Savigny e pela teoria da interpretação kelseniana (que separa atos de cognição e de vontade).

Para Gadamer a aplicação constitui o cerne do acontecimento da compreensão, em os efeitos atuais do passado ou a história efetiva (Wirkungeschichte) estão sempre em jogo. Não podemos escapar deste ponto de partida, pois o intérprete está antecipadamente envolvido pelo mundo e pelo objeto que põe em questão. Interpretamos um texto a partir de pré-conceitos e, assim, projetamos nele um sentido. Nossos projetos devem ser modificados no processo: o todo (uma visão de mundo) dá sentido à compreensão da parte e, esta última, recursivamente, modifica o todo.

A circularidade do movimento implica no fato de que sempre aplicamos o sentido que entendemos à situação particular na qual nos encontramos. Gadamer escreve: “compreender 'a coisa' que surge ali, diante de mim, não é outra coisa senão elaborar um primeiro projeto que se vai corrigindo, progressivamente, à medida que progride a decifração"22. Compreensão, interpretação e aplicação coincidem, pois não podemos escapar do nosso horizonte prévio de compreensão, ou seja, nós nos levamos para dentro da compreensão, estando assim a compreensão co-determinada por nossa história ${ }^{23}$.

Nunca estamos plenamente conscientes de tudo o que é aplicado (os efeitos da história) no acontecimento da compreensão; podemos, contudo, tornarmo-nos conscientes dos nossos próprios limites e de que somos seres fundamentalmente históricos. É isso que Gadamer chama de consciência histórica. Investigar o seu papel é uma tarefa mais fecunda para as ciências humanas do que a elaboração de planos metodológicos voltados ao controle da interpretação.

Contra o argumento de que tal postura levaria a um relativismo, o filósofo defende que a consciência de nossa pertença à história impulsiona o movimento no círculo compreensivo e que é justamente esse movimento (que se opõe à estagnação daquele que não reconhece sua conexão com o contexto) que fornece legitimidade para o saber. Trata-se, portanto, de reconhecer a existência de um critério de legitimação do conhecimento diferente daquele estabelecido pelas ciências naturais.

É com o objetivo de elucidar a maneira pela qual esse outro saber pode ser exercido que Gadamer recorre ao exemplo da hermenêutica jurídica. Ao lidar com um caso concreto, o juiz tem que considerar diretrizes já estabelecidas e que precisam ser integradas no tempo

${ }^{22}$ GADAMER, Hans Georg. 0 problema da consciência histórica. Rio de Janeiro: Editora FGV, 2003 . p 61. ${ }^{23} \mathrm{Cf}$. GADAMER, Hans Georg. Verdade e método I: traços fundamentais de uma hermenêutica filosófica. Petrópolis: Ed. Vozes, 2002. DUTT, Carsten. En conversación con Hans-Georg Gadamer - Filosofia, estética e filosofia prática. Madri: Editorial Tecnos, 1998. 
atual, sua atividade ilustra assim uma mediação entre passado e presente que, na verdade, ocorre em toda compreensão, assim, "a hermenêutica jurídica recorda em si mesma o autêntico procedimento das ciências do espírito"24.

A palavra jurisprudência (história da aplicação de normas jurídicas a casos concretos) ilustra o aspecto produtivo da historicidade. Como recorda Grondin ${ }^{25}$, jurisprudência evoca a prudência. A aplicação da norma não é resultado de um método no qual um caso particular é automaticamente subsumido a uma regra geral, tampouco é sinônimo de puro arbítrio. Deve ser compreendida como prudência, isto é, como consciência da força do passado e da possibilidade de sua transformação no presente. Aquele que decide seriamente no âmbito jurídico levará em consideração a história das decisões (jurisprudência) e sua incomensurabilidade para que, então, possa chegar a uma decisão melhor.

A explicação da atividade do jurista prático em termos dicotômicos (ou se aproximaria de modelos cognitivistas ou seria completamente arbitrária) deixa de lado o debate sobre sua relação com a prudência e com a ética. A norma jurídica pode ser aplicada, prudentemente, de formas diferentes em casos diferentes e tal variação não deve ser pensada como simples arbitrariedade, é uma exigência da atividade prática dos juristas.

\section{A IMPORTÂNCIA DA PHRÓNESIS ARISTOTÉLICA}

As reflexões gadamerianas sobre prudência e ética têm como ponto de partida a retomada da filosofia prática de Aristóteles. Gadamer explica seu projeto: “Tentarei mostrar que a filosofia prática de Aristóteles - e não o conceito de método moderno e ciência - é o único modelo viável para formarmos uma ideia de ciência do espírito"26. De fato, a filosofia aristotélica da práxis assume um elemento que as ciências da natureza, nascidas do espírito geométrico, não são capazes de abarcar, a saber, a prudência ou a phrónesis, isto é, a disposição racional verdadeira e prática a respeito do que é bom para o ser humano.

O exercício da phrónesis é, em Aristóteles, sempre uma realização da justiça como equidade, que realça o caráter circunstancial de toda decisão prática. A recuperação desse outro tipo de saber pela hermenêutica filosófica pode nos fornecer meios para repensar um

\footnotetext{
${ }^{24}$ GADAMER, Hans Georg. Verdade e método I: traços fundamentais de uma hermenêutica filosófica. Petrópolis: Ed. Vozes, 2002. p. 487.

${ }^{25}$ GRONDIN, Jean. Gadamer's Interest for legal hermeneutics. In: Law's hermeneutics: other investigations, Routledge : Oxford, 2017. pp. 48-62.

${ }^{26}$ GADAMER, Hans Georg. Verdade e método I: traços fundamentais de uma hermenêutica filosófica. Petrópolis: Ed. Vozes, 2002. p. 440.
} 
dilema constante na teoria do direito, que tende a oscilar entre respostas cognitivistas (que podemos identificar tanto na tradição do formalismo jurídico como nas propostas de Betti e Esser) e irracionalistas (como o decisionismo de Carl Schmitt). Gadamer escreve:

Se o próprio núcleo do problema hermenêutico é que a tradição como tal deve ser compreendida cada vez de modo diferente, então - a partir do ponto de vista lógico - o que está em questão é a relação entre o geral e o particular. Compreender passa a ser um caso especial da aplicação de algo geral a uma situação concreta e particular. ${ }^{27}$

Em seguida, o filósofo explica como a questão está intrinsecamente ligada à ética aristotélica:

O problema é então saber como pode se dar um saber teórico sobre o ser ético do homem. Se o que é bom para o homem se dá cada vez na concreção da situação prática em que ele se encontra, então o saber ético deve chegar a discernir de certo modo o que é que esta situação concreta exige dele ou, dito de outro modo, aquele que atua deve ver a situação concreta à luz do que se exige dele em geral. Negativamente, significa que um saber geral que não saiba aplicar-se à situação concreta permanece sem sentido, e até ameaça obscurecer as exigências concretas que emanam de uma determinada situação ${ }^{28}$.

Em vez da exatidão do nível máximo como a que nos fornece a matemática, na filosofia prática "se trata de tão somente tornar visível o perfil das coisas e de ajudar de certo modo a consciência moral com este esboço de mero perfil"29. Aristóteles não se satisfaz com a ideia platônica de bem, que, segundo ele, seria uma generalidade vazia. Interessa-se pelo bem do ser humano, que é um ser em situação e, por isso, vive os princípios nos acontecimentos singulares.

A sabedoria prática não é o conhecimento puro, mas discernimento que define a conduta moral. Percebamos que a retomada da sensibilidade aristotélica pela vida concreta está intimamente ligada a uma das teses centrais da hermenêutica gadameriana: a situação em que atuamos não é um objeto do qual podemos nos separar, mas o horizonte que nos inclui ${ }^{30}$.

Gadamer reconstrói a distinção aristotélica entre episteme, techné e a phrónesis (ou sabedoria prática). A episteme se refere a verdades universais abstraídas das circunstâncias; de outro lado, a phrónesis e a techné estão dirigidas à aplicação do conhecimento a uma tarefa

${ }^{27}$ GADAMER, Hans Georg. Verdade e método I: traços fundamentais de uma hermenêutica filosófica. Petrópolis: Ed. Vozes, 2002. p. 441.

${ }^{28}$ GADAMER, Hans Georg. Verdade e método I: traços fundamentais de uma hermenêutica filosófica. Petrópolis: Ed. Vozes, 2002. p. 442.

29 GADAMER, Hans Georg. Verdade e método I: traços fundamentais de uma hermenêutica filosófica. Petrópolis: Ed. Vozes, 2002. p. 413.

${ }^{30}$ Cf. ARISTÓTELES. Ética a Nicômaco. São Paulo: Atlas, 2009. GADAMER, Hans Georg. A ideia do bem entre Platão e Aristóteles. São Paulo: Martins Fontes, 2009. 
ISSN 1981-3694

(DOI): $10.5902 / 1981369435161$

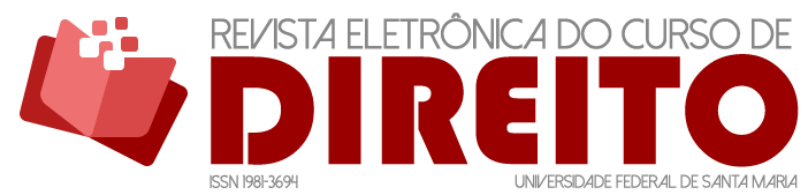

ACERCA DO INTERESSE DE HANS-GEORG GADAMER PELO DIREITO

Mariana Pimentel Fischer PACHeco ALESSANDRA MACEDO ASFORA

humana particular, mas não se confundem exclusivamente com a experiência, pressupõem um saber prático ajustado à concreção da atividade humana.

A phrónesis difere da techné, pois aquela se relaciona com a práxis e esta com a poiésis. A techné tem como finalidade a fabricação de um produto (ergón), já a phónesis está ligada a uma práxis (energeia) e visa à ação virtuosa. Como explica Gadamer, a phrónesis difere de techné, pois, "o homem não dispõe de si mesmo como o artesão dispõe da matéria com que trabalha" ${ }^{11}$. Na techné, a imagem final do objeto a ser fabricado já está previamente dada, o material usado pelo artesão é substituível. De outra parte, o saber moral da phrónesis não permite que um conceito ou imagem domine por completo a situação.

Um repertório de ideias sobre justiça, bem comum e solidariedade são, sem dúvida, diretrizes, mas necessitam sempre ser adaptadas à situação. Se um artesão não tem à mão o material que gostaria para realizar seu trabalho, pode renunciar a seu plano inicial e adaptá-lo (como acontece na phrónesis). Entretanto, esta não é uma exigência própria da sua ocupação (diferente da phrónesis), é sim, para ele, um problema. O artesão provavelmente ficará frustrado pela deficiência dos meios. Na aplicação do direito ou na deliberação moral, há sempre que se adaptar conceitos genéricos ao caso. Isso não ocorre por conta de uma dificuldade prática, a adaptação é uma exigência de justiça.

Diferentemente da techné, que se refere a um saber específico e serve a fins determinados, a phrónesis remete a um cuidado pela vida em geral. Fins justos não podem ser objetificados. Aprende-se a phrónesis com a experiência integral de vida, não pelo acúmulo de informações ou desenvolvimento de uma habilidade específica. Por isso Aristóteles diz que a phrónesis não pode ser ensinada como uma techné.

A phrónesis é uma atividade ética no sentido que os gregos atribuíram à palavra, referese a um modo de vida, envolve convicções e costumes que conformam a maneira pela qual habitamos o mundo. Para Gadamer, trata-se de zelar pelo que é comum, sem deixar de lado o potencial criativo que há na abertura à singularidade de um acontecimento. A phrónesis é uma espécie de "moralidade encarnada" 32 na medida em exige que nos deixemos formar pela vida concreta.

Constitui um saber que leva a sério o acontecimento integral, que acontece no tempo, e por isso está sempre exposto à revisão. Nesse sentido, reivindica o reconhecimento da alteridade que está aí. Gadamer (2002b) escreve: “O homem compreensivo não sabe nem julga a partir de

${ }^{31}$ GADAMER, Hans Georg. Verdade e método I: traços fundamentais de uma hermenêutica filosófica. Petrópolis: Ed. Vozes, 2002. p. 418.

32 HERMANN, Nadja. Ética e estética: a relação quase esquecida. Porto Alegre: EDIPUCRS, 2005. p 105. 
ISSN 1981-3694

(DOI): $10.5902 / 1981369435161$

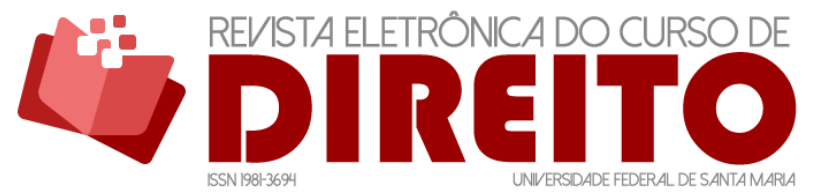

ACERCA DO INTERESSE DE HANS-GEORG GADAMER PELO DIREITO

MARIANA PIMENTEL Fischer PACHECO ALESSANDRA MACEDO ASFORA

uma situação externa e não afetada, mas a partir de uma pertença específica que o une ao outro, de modo que é afetado com ele e pensa com ele" ${ }^{\text {33 }}$.

A ética gadameriana está baseada em relações fáticas e afetivas com o outro. A solidariedade vivida faz parte da formação da comunidade e de toda decisão ética tomada nela. Não há garantias a respeito da decisão a que se chegará a partir de tais práticas, mas nisso reside um ponto crucial: a hermenêutica mostra os perigos do apego a sistemas morais impostos de antemão, que retiram do ser humano a responsabilidade pela decisão. Trata-se de carregar o peso de pensar autonomamente os fins e os fundamentos.

Ainda que Aristóteles geralmente afirme que a phrónesis está conectada com os meios, o filósofo insiste também que ela não consiste na mera capacidade de elegê-los: um telos (uma finalidade) guia aquele que age eticamente. A ponderação dos meios (que é ela mesma moral) concretiza a moralidade de seus fins ${ }^{34}$.

\section{O SABER DA PRÀXIS}

Mostramos que a phrónesis aristotélica não se reduz nem à episteme, nem a techné. 0 saber da phrónesis depende da maneira de ser de cada ser humano consigo mesmo, com os outros e com o mundo. Esse modo de ser se constitui por meio da educação, dos hábitos, disposições e desejos, isto é, do ethos. Nesse sentido, a ação ética não está essencialmente determinada por um saber, mas por um saber-fazer.

Aristóteles tenta equilibrar a herança socrático-platônica com sua própria concepção de ethos. Como dito, não entende o ethos como um repertório de normas externas impostas ao sujeito, tampouco como um dom inato. 0 ethos se constrói na vida comum.

Deixar-se guiar pelo ethos não significa, contudo, desvincular-se da reflexão racional que faz presente os fins últimos em direção aos quais a ação se dirige. Recordemos que Aristóteles distinguia as virtudes éticas das dianoéticas e as situava em diferentes partes da alma racional, mas também se perguntava se esses não seriam dois aspectos do mesmo, como na circunferência o são o convexo e o côncavo ${ }^{35}$.

\footnotetext{
33 GADAMER, Hans Georg. Verdade e método II - Complementos e Índice. Petrópolis: Vozes, 2002. p. 395.

${ }^{34}$ Cf. GADAMER, Hans Georg. 0 problema da consciência histórica. Rio de Janeiro: Editora FGV, 2003. GADAMER, Hans Georg. A ideia da filosofia prática. In: Hermenêutica em retrospectiva III. Petrópolis: Vozes, 2007.

${ }^{35}$ ARISTÓTELES. Ética a Nicômaco. São Paulo: Atlas, 2009.
} 
A phrónesis é o saber ético que se constitui na experiência, consiste em deliberar bem com os outros a partir da posição em que nos encontramos; assim, em vez de mera dedução, a aplicação ganha o sentido de mediação e co-determinação entre universal e particular:

A virtude aristotélica da racionalidade, phrónesis, acaba sendo a virtude hermenêutica fundamental. Serviu de modelo para minha própria linha argumentativa. Desse modo, a hermenêutica, essa teoria da aplicação, quer dizer, da conjugação do universal e do particular, converteu-se para mim numa tarefa filosófica central ${ }^{36}$.

O problema da conjugação entre universal e particular, em Aristóteles, não se apresenta sem dificuldades. A tensão maior está justamente no modo aristotélico de pensar a mediação entre logos (subjetividade do saber, isto é, particularidade) e ethos (substancialidade do ser, isto é, universalidade).

Gadamer argumenta que esses seriam dois lados da mesma moeda. A virtude está conectada ao logos, mas ocorre na vida como sabedoria prática, recebe, portanto, a marca do ethos. Eis a peculiaridade da concepção gadameriana de racionalidade: a racionalidade (Vernünftigkeit) é o exercício consciente e responsável das decisões e ações humanas ${ }^{37}$. Diferentemente de uma racionalidade técnico-pragmática (coordenadora dos meios e fins), essa outra racionalidade intervém na práxis vital e tem a estrutura dialética de uma "generalidade concreta"38.

Universal é o fato de que a compreensão é sempre mediada linguisticamente e, por essa razão, nela atuam valores éticos, sociais e estéticos. Quem compreende participa do que é compreendido do mesmo modo que o saber prático de Aristóteles depende daquele que o exerce; por isso é, no final das contas, um saber-se (Sich-Wissen). 0 tipo de universalidade que corresponde ao conhecimento ético reconhece que a interpretação se realiza de diferentes modos, posto que é um universal que há de ser aplicado a situações particulares.

Para que possamos compreender melhor a ligação entre ética e decisões prudentes e engajadas em práticas vitais, devemos examinar com mais profundidade o argumento de Aristóteles segundo o qual a phrónesis não pode ser ensinada, isto é, não se constitui por meio

\footnotetext{
${ }^{36}$ GADAMER, Hans Georg. Verdade e método I: traços fundamentais de uma hermenêutica filosófica. Petrópolis: Ed. Vozes, 2002. p. 380

${ }^{37}$ Cf. GADAMER, Hans Georg. Verdade e método I: traços fundamentais de uma hermenêutica filosófica. Petrópolis: Ed. Vozes, 2002. GADAMER, Hans Georg. A ideia do bem entre Platão e Aristóteles. São Paulo: Martins Fontes, 2009.

${ }^{38}$ GADAMER, Hans Georg. Verdade e método II - Complementos e Índice. Petrópolis: Vozes, 2002. p. 380.
} 
do acúmulo de informações que podem ser transmitidas de um ser humano para outro. Gadamer dirá que o saber da phrónesis se aprende por meio de uma formação (Bildung) pela experiência.

O ser humano prudente ou o ser humano experimentado não é exatamente um erudito (não é aquele que possui uma grande quantidade de informações sobre um assunto), mas alguém capaz de deliberar bem. Para isso, precisa ter consciência de que participa do que compreende: o tecido de sentido que vai se revelando na interpretação carrega o potencial de mostrar a indeterminação que faz parte do próprio intérprete. Insistamos que o saber prático é um saberse o qual permite a realização da processualidade vital a partir de sua força negativa de destipificação de universais.

A aplicação não é o emprego posterior de algo universal, compreendido primeiro em si mesmo, e depois aplicado a um caso concreto. É, antes, a verdade compreensão do próprio universal que todo texto representa para nós. A compreensão é uma forma de efeito e se sabe a si mesma como tal efeito ${ }^{39}$

A experiência não é entendida aqui como aquilo que meramente informa; indica sim a maneira pela qual a história atua no intérprete. Como a experiência não cabe na consciência, envolve sempre frustração de planos, ela é, nesse sentido, capaz de revelar nossa própria finitude. Ao contrário do dogmático que resiste à negação de seu sistema, o hermeneuta, que adquire consciência histórica, aceita a negatividade da experiência e, mais ainda, faz dela sua companheira de jornada.

O homem experimentado conhece os limites de toda previsão e a insegurança de todo plano. Nele consuma-se o valor de verdade da experiência. Nela chega ao limite absoluto todo dogmatismo nascido do coração humano que se deixa possuir por seus desejos. A experiência ensina a reconhecer o que é real ${ }^{40}$.

Abertura conecta-se a um impulso para deixar algo valer contra o intérprete e, assim, fazer presente o impacto de um acontecimento concreto. A experiência ensina, portanto, os limites do outro e a mobilidade das coisas. Seguindo Heidegger, Gadamer traduz phrónesis por Gewissen ou consciência que orienta a ação à eleição autêntica para si mesmo ${ }^{41}$. Racionalidade prática comporta uma ética, pois se constitui em uma situação em que o outro está

\footnotetext{
${ }^{39}$ GADAMER, Hans Georg. Verdade e método I: traços fundamentais de uma hermenêutica filosófica. Petrópolis: Ed. Vozes, 2002. p. 446.

${ }^{40}$ GADAMER, Hans Georg. Verdade e método I: traços fundamentais de uma hermenêutica filosófica. Petrópolis: Ed. Vozes, 2002. p 467.

${ }^{41}$ GADAMER, Hans Georg. A razão na época da ciência. Rio de Janeiro: Tempo Brasileiro, 1983
} 
ISSN 1981-3694

(DOI): $10.5902 / 1981369435161$

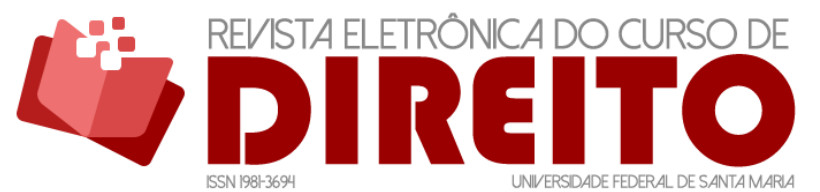

ACERCA DO INTERESSE DE HANS-GEORG GADAMER PELO DIREITO

inevitavelmente presente. Efetivamente, a compreensão requer colocar-se no lugar do outro, supõe uma ligação e um compromisso por uma causa justa.

Para Gadamer, a hermenêutica jurídica realiza a prudência e a sabedoria prática que podem ser entendidas como base legitima das decisões que precisam ser tomadas na atualidade. Insistamos que reconhecer a historicidade das razões jurídicas não significa afirmar o relativismo no campo do direito. Muito pelo contrário, a sabedoria jurisprudencial é exemplo do jogo produtivo entre passado e presente.

\section{CONCLUSÃO}

Lembrar o que Gadamer escreveu sobre o direito significa revigorar aspectos de seu trabalho que foram obscurecidos pela tradição e trazer à tona ideias importantes para o debate atual entre juristas.

Em primeiro lugar, pensar a partir da hermenêutica gadameriana significa abandonar uma perspectiva cognitivista. Implica em problematizar o modelo de objetividade das ciências exatas que está na base de concepções matematizantes do raciocínio jurídico defendidas por diferentes versões do formalismo. Outrossim, como vimos, o cognitivismo está também presente em perspectivas críticas ao formalismo jurídico (como o ponto de vista de Esser), as quais não conseguiram deixar para trás a ideia de que as tarefas de conhecimento e aplicação da norma podem ser separadas.

Tais pontos de vista negligenciam a tese da unidade entre compreensão, interpretação e aplicação e sua associação com o fato de que o pertencimento do intérprete a uma tradição pode ter um caráter produtivo. Como diz Gadamer, preconceitos contra preconceitos estão na base do modelo moderno de objetividade.

A crítica ao cognitivismo não leva necessariamente a um relativismo, como no decisionismo em suas diversas versões. Nenhuma das duas perspectivas reconhece a peculiaridade da estrutura argumentativa do direito e suas exigências de equidade. Mesmo que a mentalidade dos juízes esteja fortemente formatada por ideias cognitivistas (principalmente advindas do formalismo jurídico) seu saber-fazer (que não é apenas teórico) demanda maleabilidade, exige adaptação no processo de interpretação/compreensão/aplicação da norma ao caso concreto.

Os juristas práticos realizam essa tarefa ética de adaptação, nesse sentido, sua atividade é, para Gadamer, exemplo de um saber legítimo. O problema é que grande parte dos 
juristas teóricos (filiados a tradições cognitivistas ou relativistas) não conseguem enxergar a relevância do componente prudencial pertencente à atividade cotidiana dos julgadores.

Retomar lições gadamerianas significa, portanto, abrir espaço para outro saber sobre o direito, um tipo de saber que zela pela vida concreta e por sua conexão com a ética. 0 reconhecimento da indissociabilidade entre compreensão, interpretação e aplicação pode ajudar os juristas a perceber os efeitos da história no presente e atentar para a importância da prudência e da equidade nos julgamentos. O hermeneuta sabe que se arrisca sempre que decide e reconhece o peso e a responsabilidade de quem pensa autonomamente os fundamentos e a finalidade de suas escolhas.

Por fim, devemos recordar que o retorno a Aristóteles no pós-guerra não foi um caminho escolhido exclusivamente por Gadamer. Theodor Viehweg (1979) publicou em 1953 Tópica e Jurisprudência e, logo em seguida, em 1958, Chaim Perelman (1996) publicou Tratado de Argumentação: a Nova Retórica. Esses autores também retomaram o filósofo e se tornaram matrizes de diversas tendências, conhecidas, hoje, como Teorias da Argumentação jurídica.

Ressaltemos, no entanto, que a leitura de Aristóteles realizada por Gadamer difere da perspectiva das Teorias da Argumentação. Nessas últimas podemos identificar ou um descompromisso com o problema da eticidade ou sua reformulação em termos de um debate de matriz kantiana (e não aristotélica) sobre moralidade (esse é o caso de Robert Alexy e Klaus Günther). Insistamos que a peculiaridade das reflexões gadamerianas sobre o direito está justamente na maneira pela qual o filósofo situa sua leitura de Aristóteles no interior de um questionamento ontológico e de uma discussão acerca da ética.

Os limites da perspectiva gadameriana também não podem ser olvidados. Não existiria alguma espécie de idealização na investigação de Gadamer sobre a hermenêutica jurídica? Insistir, hoje, no Brasil, em uma valorização da prudência não pode servir como escusa para o excessivo afrouxamento do vínculo de decisões a normas jurídicas e, assim, contribuir para a reprodução de padrões sociais arraigados de troca de influencia econômica e política? Como pensar a partir de Gadamer e ao mesmo tempo evitar esse tipo de dificuldade?

Decerto, as teses gadamerianas acerca da hermenêutica jurídica necessitam ser complementadas por filósofos e juristas. Vimos que nem a Jurisprudência Hermenêutica nem as Teorias da Argumentação conseguem dar conta do questionamento gadameriano em toda sua densidade e extensão. De outro lado, as reflexões de Paul Ricoeur sobre "o Justo" apontam para um caminho que nos parece mais produtivo, já que buscam dar continuidade ao esforço gadameriano de maneira a pensar a conexão entre ética e práticas jurídicas. Pretendemos aprofundar nossa investigação acerca de sua proposta em trabalhos futuros. 


\section{REFERÊNCIAS}

ARISTÓTELES. Ética a Nicômaco. São Paulo: Atlas, 2009.

BARBOSA, Samuel. Jus Cogens como aporia: o crepúsculo do direito internacional clássico. Revista Brasileira de Filosofia, v. 58, n 233, p 37-85, 2009.

BETTI, Emilio. Teoria generale dell' interpretazione. 2 vols. Milão: Giuffrè, 1955.

CALSAMIGLIA, Albert. Postpositivismo. In: Doxa, n. 17/18. Alicante: Universidad de Alicante, 2005

DUTT, Carsten. En conversación con Hans-Georg Gadamer - Filosofia, estética e filosofia prática. Madri: Editorial Tecnos, 1998.

ESSER, Josef. Precomprensione e scelta del método nel processo di individuazione del diritto. Camerino: Edizioni Scientifiche Italiane, 1983.

GADAMER, Hans Georg. A razão na época da ciência. Rio de Janeiro: Tempo Brasileiro, 1983.

GADAMER, Hans Georg. 0 problema da consciência histórica. Rio de Janeiro: Editora FGV, 2003.

GADAMER, Hans Georg. A ideia da filosofia prática. In: Hermenêutica em retrospectiva III. Petrópolis: Vozes, 2007.

GADAMER, Hans Georg. A ideia do bem entre Platão e Aristóteles. São Paulo: Martins Fontes, 2009.

GADAMER, Hans Georg. Verdade e método I; traços fundamentais de uma hermenêutica filosófica. Petrópolis: Ed. Vozes, 2002.

GADAMER, Hans Georg. Verdade e método II - Complementos e Índice. Petrópolis: Vozes, 2002.

GRONDIN, Jean. Gadamer: una biografia. Milão: Bompiani, 2004.

GRONDIN, Jean. La hermenéutica como ciencia rigurosa según Emilio Betti (1890-1968). Revista Co-herencia Vol. 8, No 15 Julio - Diciembre 2011, pp. 15-44. Medellín, Colombia.

GRONDIN, Jean. Gadamer's Interest for legal hermeneutics. In: Law's hermeneutics: other investigations, Routledge : Oxford, 2017. pp. 48-62.

HERMANN, Nadja. Ética e estética: a relação quase esquecida. Porto Alegre: EDIPUCRS, 2005. JUST, Gustavo. Interpretando as teorias da interpretação. São Paulo: Saraiva, 2014

SALDANHA, Nelson: Ordem e Hermenêutica. Rio de Janeiro: Renovar, 2003.

SAVIGNY, Friedrich Carl von. Sistema del Derecho Romano Actual. Alicante: Biblioteca Virtual Miguel de Cervantes, 2009. 


\section{COMO FAZER REFERÊNCIA AO ARTIGO (ABNT):}

PACHECO, Mariana Pimentel Fischer; ASFORA, Alessandra Macedo. Acerca do interesse de Hans-Georg Gadamer pelo Direito. Revista Eletrônica do Curso de Direito da UFSM, Santa Maria, RS, v. 14, n. 2, e35161, maio./ago. 2019. ISSN 1981-3694. DOI: http://dx.doi.org/10.5902/1981369435161. Disponível em:

https: //periodicos.ufsm.br/revistadireito/article/view/35161 Acesso em: dia mês. ano.

Direitos autorais 2019 Revista Eletrônica do Curso de Direito da UFSM

Editores responsáveis: Rafael Santos de Oliveira e Angela Araujo da Silveira Espindola

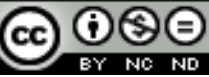

Esta obra está licenciada com uma Licença Creative Commons Atribuição-NãoComercial-SemDerivações 4.0 Internacional.

\section{SOBRE AS AUTORAS}

MARIANA Pimentel Fischer Pacheco

Possui mestrado (2004) e doutorado (2009) em Filosofia do Direito pela Universidade Federal de Pernambuco (UFPE), pósdoutorado (2018) em Filosofia pela Universidade de São Paulo (USP). Atualmente é Professora Adjunta em regime de Dedicação Exclusiva do Centro de Ciências Jurídicas da UFPE. É pesquisadora (colaboradora) do Núcleo de Estudos da Violência (NEV)/ USP - especificamente em trabalhos realizados pela parceira entre o NEV/USP e o Instituto de Pesquisa Social da Universidade J. W. Goethe em Frankfurt -, pesquisadora do Núcleo de Estudos em Filosofia Política e Ética (NEFIPE) /UFPE e do Grupo de Estudos sobre Teoria Social e Subjetividades (GETSS)/UFPE. Tem experiência nas áreas de Direito, Filosofia e Teoria Social, atuando principalmente nos seguintes temas: democracia, ética, teoria crítica e gênero.

\section{ALESSANDRA MACEDO ASFORA}

Doutora em Direito Pela Universidade Federal de Pernambuco (2017), mestre em Direito pela Universidade Federal de Pernambuco (2006), com concentração em Teoria e Filosofia do Direito; Graduada em Direito pela Universidade Católica de Pernambuco (2000). Atualmente é professora adjunta da Universidade Federal da Paraíba (2008), lecionando Direito Civil, Metodologia da Pesquisa Jurídica e Teoria do Direito. Em Pernambuco, é professora de Direito Civil e Hermenêutica Jurídica na Faculdade Damas(2011). Com experiência nas áreas de Direito civil e Filosofia do Direito, atua principalmente nos seguintes temas: metodologia da pesquisa Jurídica, hermenêutica Jurídica, história do direito civil, teoria do fato jurídico, constitucionalização do direito civil. 